\title{
Correlação entre a pressão arterial média e o fluxo sangüíneo na artéria oftalmica externa em gatos (felis catus linnaeus, 1758)
}

Gentil Ferreira GONÇALVES'

Ney Luis PIPPI ${ }^{2}$

Marshal Costa LEME

Amaury Teixeira

CUSTÓDIO ${ }^{3}$

Aristeu Vieira da SILVA ${ }^{1}$

Patrícia ROMAGNOLLI ${ }^{1}$

José Ricardo PACHALY

João Marco Pancera BOTTIN 4

Francislaine Aparecida dos

Reis LIVERO ${ }^{4}$

Correspondência para:

R. Fortaleza, 4031. Jd. América. Umuarama

-PR.87502-300.gentil.vet@unipar.br

Recebido para publicação: 09/03/2005 Aprovado para publicação: 25/10/2007

\author{
1 - Curso de Medicina Veterinária da Universidade Paranaense, Umuarama - PR \\ 2 - Universidade Federal de Santa Maria, Santa Maria - RS \\ 3 - Médico, Especialista em Diagnóstico por Imagem. Membro do Colégio Brasileiro \\ e Inter-Americano de Radiologia - SP \\ 4 - Médico Veterinário Autônomo, Umuarama - PR
}

\section{RESUMO}

Foram utilizados 20 gatos sem raça definida, com massa corpórea entre 2 e 4 quilogramas, hígidos, anestesiados com tiletamina e zolazepam $(6,0 \mathrm{mg} / \mathrm{kg})$. A artéria femoral foi canulada de forma asséptica e um manômetro acoplado a uma coluna de ar foi conectada ao cateter, a PAM foi aferida antes e a cada 15 minutos até o término do exame ultra-sonográfico. A fluxometria da artéria oftálmica externa foi obtida através do equipamento de ultra-sonografia dotado de eco-doppler, com transdutor setorial de 6,0 $\mathrm{MHz}$, aplicado diretamente sobre a córnea. Cada olho teve o fluxo de sua artéria aferido pelo programa do próprio aparelho, sendo tomadas três amostras. O índice de resistência vascular foi calculado com base nos valores do fluxo sistólico e diastólico médio de cada vaso. Obteve-se um valor médio para a PAM de 144,9 $\pm 26,68 \mathrm{mmHg}$ e uma velocidade de fluxo de $41,3 \pm 14,28 \mathrm{~cm} / \mathrm{s}$ para a artéria oftálmica externa no olho direito em sístole, 23,95 \pm 11,46 cm/s em diástole e 42,75 \pm 12,64 $\mathrm{cm} / \mathrm{s}$ no olho esquerdo em sístole, $25,45 \pm 9,61 \mathrm{~cm} / \mathrm{s}$ em diástole, não existindo diferença significativa entre os olhos. $O$ índice de resistência vascular calculado foi de 0,4175 para a artéria oftálmica externa no olho direito e 0,4015 para a do olho esquerdo, sem diferença significativa entre os olhos. Os resultados apontam para um mecanismo intrínseco de controle do fluxo, controlado por fatores locais na artéria oftálmica externa. Os valores do índice de resistência denotam uma artéria de baixo fluxo. Como conclusão, têm-se os valores de referência acima citados para a PAM e para o fluxo sangüíneo na artéria oftálmica externa em gatos sem raça definida anestesiados com tiletamina e zolazepam, e a informação de que não existe correlação entre esses valores.

\section{Introdução}

A aferição da pressão arterial em pequenos animais está se tornando uma prática de rotina, principalmente na clínica cirúrgica. Devido ao fato dos pacientes, na maioria dos casos, necessitarem de uma abordagem anestésica em algum momento. Os estudos em avaliações de pressão arterial já são antigos sendo o primeiro dado de $1733^{1}$, porém os métodos utilizados atualmente são modernos e mais práticos.
Com as facilidades na aquisição de equipamentos e o aumento no número de problemas relacionados à pressão arterial em pequenos animais, principalmente em gatos, se fazem necessários estudos que retratem a realidade desses animais no Brasil.

Em várias doenças oftálmicas, como retinopatia diabética, glaucoma e hipertensão, existem alterações significativas no padrão vascular ocular. A identificação dessas alterações é importante, pois auxilia na programação de condutas terapêuticas. 
Segundo Diniz et al. ${ }^{2}$, existe grande interesse em se desenvolver novas técnicas não invasivas, acessíveis e reprodutíveis para o estudo da vascularização ocular.

Existem relatos de alterações oftálmicas relacionadas à pressão arterial produzindo lesões em áreas nobres do olho, muitas vezes levando o animal à uma perda irreversível da visão. As principais lesões são vasos retinianos tortuosos, hemorragia de vítreo e retina, descolamentos de retina de tamanhos variados e degeneração de retina. ${ }^{3,4,5}$

A pressão arterial média (PAM) oscila de acordo com vários fatores, entre eles, alterações metabólicas por distúrbios de filtração renal. Não se conhece até o momento a relação entre o fluxo da artéria oftálmica externa e a PAM em gatos, ou mesmo se ela existe.

O objetivo desse estudo se refere à obtenção de valores de referência da PAM e do fluxo sangüíneo (FS) da artéria oftálmica externa em gatos domésticos sem raça definida, e obter uma correlação entre elas. Esses dados poderão servir como parâmetros em futuras pesquisas, para uso na rotina oftálmica e até extrapolação para outras espécies como seres humanos.

\section{Material e Método}

Foram utilizados 20 gatos sem raça definida, provenientes da Sociedade de Amparo aos Animais de Umuarama - PR (SAAU), com massa corpórea entre dois e quatro quilogramas, sendo 12 machos e oito fêmeas, com idades entre um e cinco anos. Os animais foram submetidos a exame físico geral e oftálmico, para comprovação de sua boa condição sistêmica e oftálmica. O exame físico utilizou-se de inspeção visual de pele, pêlos e mucosas, termometria retal, auscultação respiratória e cardíaca, e palpação de extremidades, linfonodos e órgãos abdominais. O exame oftálmico constou de observação com iluminação direta e lupa de superfícies externas, tais como mucosas e pele, teste lacrimal de Schirmer tipo I, oftalmoscopia direta e, por fim, palpação do bulbo ocular. Os animais foram alojados em recintos individuais no Setor de Clínica Médica dos Pequenos Animais do Hospital Veterinário da Universidade Paranaense UNIPAR, por um período de adaptação de não menos que 15 dias, nos quais receberam água e ração ad libitum.

Para os procedimentos experimentais os animais foram transportados em gaiolas de transporte individuais até a clínica de diagnóstico por imagem DIAGNOSE de Umuarama. Os animais foram anestesiados pela associação de tiletamina e zolazepam (Zoletil 50 $0^{\hat{a}}$ - Virbac do Brasil Ind. e Com. Ltda. - São Paulo - SP) na dose de $6 \mathrm{mg} /$ $\mathrm{kg}$ de massa corpórea, por via intramuscular. Momentos antes dos exames, os animais foram contidos manualmente e receberam a anestesia, por administração com seringa descartável de $1 \mathrm{ml}$ e agulha hipodérmica $13 \times 4,5$, no músculo longo dorsal, na região lombar.

Para o exame da PAM os animais depois de anestesiados e contidos manualmente, receberam instalação de um cateter (Angiocath 20GA x 1,16IN - Becton, Dicson Ind. Cirúrgicas Ltda. - Juiz de Fora - MG) 20 G, de forma asséptica, na artéria femoral, que era conectado a um sistema de lavagem com solução heparinizada $\left(\right.$ Heparin $^{\hat{a}}$ - Cristália Produtos Químicos farmacêuticos Ltda. - Itapira - SP) 1/1000. Para a canulação da artéria femoral os animais foram contidos em decúbito lateral esquerdo e tiveram o membro pélvico direito estendido em posição supina. Após tricotomia da região inguinal e face medial da porção proximal da perna esquerda, procedeu-se anti-sepsia da área com iodopolivinil-pirrolidona a $10 \%\left({ }^{1} \mathrm{PVPI}\right.$ degermante 10\% - Farmácia de Manipulação da UNIPAR - Umuarama - PR), seguido por álcool 70\% (Álcool 70 - Farmácia de Manipulação da UNIPAR - Umuarama PR) e por fim iodo-polivinil-pirrolidona 10\% (VPI - tópico 10\% - Farmácia de Manipulação da UNIPAR - Umuarama PR). Procedeu-se uma incisão de pele com cerca de $1,5 \mathrm{~cm}$, em sentido longitudinal ao membro, na região inguinal, imediatamente 
cranial ao músculo pectínio, localizado por palpação externa, procurando-se a região do pulso da artéria femoral. A dissecação do tecido subcutâneo e do tecido adiposo inguinal foi realizada delicadamente, sendo os vasos localizados e isolados. Após o reconhecimento e isolamento da artéria femoral, a mesma foi canulada com um cateter 20G. O mesmo foi fixado à artéria por uma ligadura com fio mononáilon 3-0 (Mononailon 3-0 - Superlon ${ }^{\hat{a}}$ - Cirumédica Ltda. - Cotia - SP), com seu canhão deixado fora da pele e obstruído por uma tampa removível estéril. Procedeu-se a limpeza do local com solução de $\mathrm{NaCl}$, $9 \%$, e realizouse sutura de aproximação nas margens de pele em um padrão de sutura isolado simples, com fio mononailon 3-0. O canhão do cateter foi fixado a pele com adesivo de cianoacrilato (Super Bonder ${ }^{\hat{a}}$ - Loctite Henkel Ltda. - São Paulo - SP).

O sistema de lavagem com coluna de ar foi confeccionado com manga de silicone semi-rígida, obtida a partir de sonda nasogástrica (Sonda mod. Levine 16 - CPL medical's - São Paulo - SP) humana, modelo Levine, número 16. Foram confeccionadas três mangas com $10 \mathrm{~cm}$ de comprimento, conectadas entre si por duas torneiras de três vias(Torneira de 3 vias Biojet - Komponent do Nordeste Ind. E Com. Ltda. - Feira de Santana - BA), tendo em uma extremidade uma conexão positiva para se acoplar ao canhão do cateter, e na outra um manômetro anaeróide (Esfigmomanômetro anaeróide - Becton, Dicson and Company - Franklin Lakes NJ - USA). A manga mais próxima da artéria servia como sistema de lavagem, sendo preenchida através da torneira de três vias com solução salina $0,9 \%$ heparinizada em uma concentração de 1/1000. A manga do meio serviu como manga de serviço e limpeza, para que a coluna de solução não atingisse a manga próxima ao manômetro, sendo drenada sempre que necessário. A manga mais distante da artéria serviu como coluna de ar, para impulsionar o cursor do manômetro e indicar a PAM, de forma contínua. A PAM foi aferida antes e a cada
15 minutos até o término do procedimento de ultra-sonografia, sendo anotadas como $\mathrm{T}_{0}$, antes do exame ultra-sonográfico e $T_{1}, T_{2}$ e $T_{3}$, com intervalos de 15 minutos entre si.

A fluxometria da artéria oftálmica externa foi obtida através do equipamento de ultra-sonografia (Toshiba Powervision ATL-HDI 3500 - Toshiba Medical do Brasil Ltda. - São Paulo - SP), dotado de ecodoppler, com um transdutor setorial de 6,0MHz. Realizou-se a aplicação tópica de uma gota de colírio anestésico (Colírio anestésico - Allergan Produtos Farmacêuticos Ltda. - Guarulhos - SP) em cada olho, e manutenção de uma espessa camada de gel aquoso (Carbogel-ult ${ }^{\hat{a}}$ Carbogel Ind. E Com. Ltda. - São Paulo SP) estéril entre a córnea e o transdutor durante a realização do exame. Após se obter imagem sagital do bulbo ocular e do nervo óptico, a artéria oftálmica externa era localizada e o cursor do Doppler era colocado sobre a mesma, a cerca de $2 \mathrm{~mm}$ da parede posterior do bulbo ocular, próximo à entrada do nervo óptico. A fluxometria era então obtida pelo programa do próprio equipamento. Foram colhidas três amostras de cada olho. O fluxo foi aferido tanto na sístole como na diástole, para em seguida se realizar a verificação do índice de resistência do vaso. $\mathrm{O}$ índice de resistência foi calculado com base na seguinte equação: $I R=F S-F D / F S$, em que, IR corresponde ao índice de resistência da artéria, FS ao fluxo sanguíneo na sístole e FD ao fluxo sangüíneo na diástole.

Obtidos os dados dos 20 animais e dos 40 olhos, os mesmos foram compilados em tabelas e submetidos a teste de comparação entre as médias, teste t de Student não pareado, para verificação da existência de diferenças significativas entre as amostras, entre os animais e entre os olhos, com um nível de significância de 5\%. Um teste de regressão logística foi utilizado para identificar a correlação entre as médias e verificação da inter-relação entre as médias da PAM e o fluxo sangüíneo da artéria oftálmica externa em sístole e em diástole. 
Após os procedimentos os animais foram encaminhados de volta ao SAAU, para posteriores doações.

\section{Resultados}

A instalação do cateter na artéria femoral foi um procedimento realizado com certa facilidade após treino, sendo necessária pequena incisão na pele. $\mathrm{O}$ problema mais freqüente observado foi a hemorragia após a retirada do cateter, a qual na maioria dos casos foi controlada por compressão externa com uma compressa de gaze. Dois animais apresentaram isquemia do membro que teve sua artéria femoral canulada, e foram submetidos à amputação do membro após 10 dias do procedimento. Um animal apresentou isquemia e automutilação três dias após o procedimento, sendo em seguida, submetido à amputação do membro, para ser preservado.

A PAM teve uma média entre os animais de $144,9 \mathrm{mmHg}$ com um desvio padrão de 26,68 mmHg. Não se observou diferença significativa entre os animais em relação à PAM (Tabela 1).

As imagens obtidas com o transdutor setorial eletrônico de $6 \mathrm{MHz}$ possibilitaram uma visualização adequada dos componentes oculares e retrobulbares. A aplicação de uma espessa camada de gel entre a córnea e o transdutor possibilitou a realização do exame de forma confortável para o animal, sem lesões à sua córnea, ou indução de reflexo óculo-cardíaco e ainda, dispensou a utilização de almofada de recuo. O equipamento ultra-sonográfico dotado de Doppler ultra-sônico possibilitou a evidenciação adequada dos vasos retrobulbares e a identificação anatômica da artéria oftálmica externa. A aferição do fluxo se deu sem problemas, visto que a manipulação do equipamento só requer treinamento (Figura 1).

O fluxo sanguíneo na artéria oftálmica externa apresentou pequena variação entre os olhos, sem diferenças significativas à verificação estatística. Os valores médios foram para o fluxo na artéria oftálmica no olho direito $41,30 \pm 14,28 \mathrm{~cm} / \mathrm{s}$ durante a sístole e 23,95 $\pm 11,46 \mathrm{~cm} / \mathrm{s}$ durante a diástole, e no olho esquerdo $42,75 \pm 12,64$ $\mathrm{cm} / \mathrm{s}$ durante a sístole e $25,45 \pm 9,61 \mathrm{~cm} / \mathrm{s}$

Tabela 1 - Valores médios aferidos de pressão arterial média, em milímetros de mercúrio, em gatos sem raça definida, anestesiados com tiletamina e zolazepam

\begin{tabular}{cc}
\hline Animais & Pressão Arterial Média (mmHg) \\
\hline G1 & 130,00 \\
G2 & 173,75 \\
G4 & 170,00 \\
G5 & 145,00 \\
G6 & 165,00 \\
G7 & 158,33 \\
G8 & 85,00 \\
G9 & 112,50 \\
G10 & 122,50 \\
G11 & 126,67 \\
G12 & 126,67 \\
G13 & 113,33 \\
G14 & 150,00 \\
G15 & 176,67 \\
G16 & 166,67 \\
G17 & 153,33 \\
G18 & 173,33 \\
G19 & 176,67 \\
G20 & 115,00 \\
\hline Média & 157,50 \\
\hline Desvio-padrão & 144,90 \\
\hline
\end{tabular}

durante a diástole (Tabela 2).

Ao se proceder ao teste de regressão logística confrontando os valores da PAM e do fluxo sangüíneo na a. oftálmica externa de ambos os olhos dos animais examinados, não se constatou correlação entre os mesmos.

O cálculo do índice de resistência vascular apresentou pequena oscilação entre os animais, não sendo evidenciada diferença significativa. $\mathrm{O}$ valor médio verificado para o índice de resistência da artéria oftálmica externa foi para o olho direito $0,4175 \pm$ 0,0774 e para o olho esquerdo $0,4015 \pm$ 0,0719 (Tabela 3).

\section{Discussão}

A anestesia dissociativa associada a um benzodiazepínico produz um estado cataleptóide, com tônus de cabeça, e boa analgesia de acordo com Lin et al. ${ }^{6}$. Este 


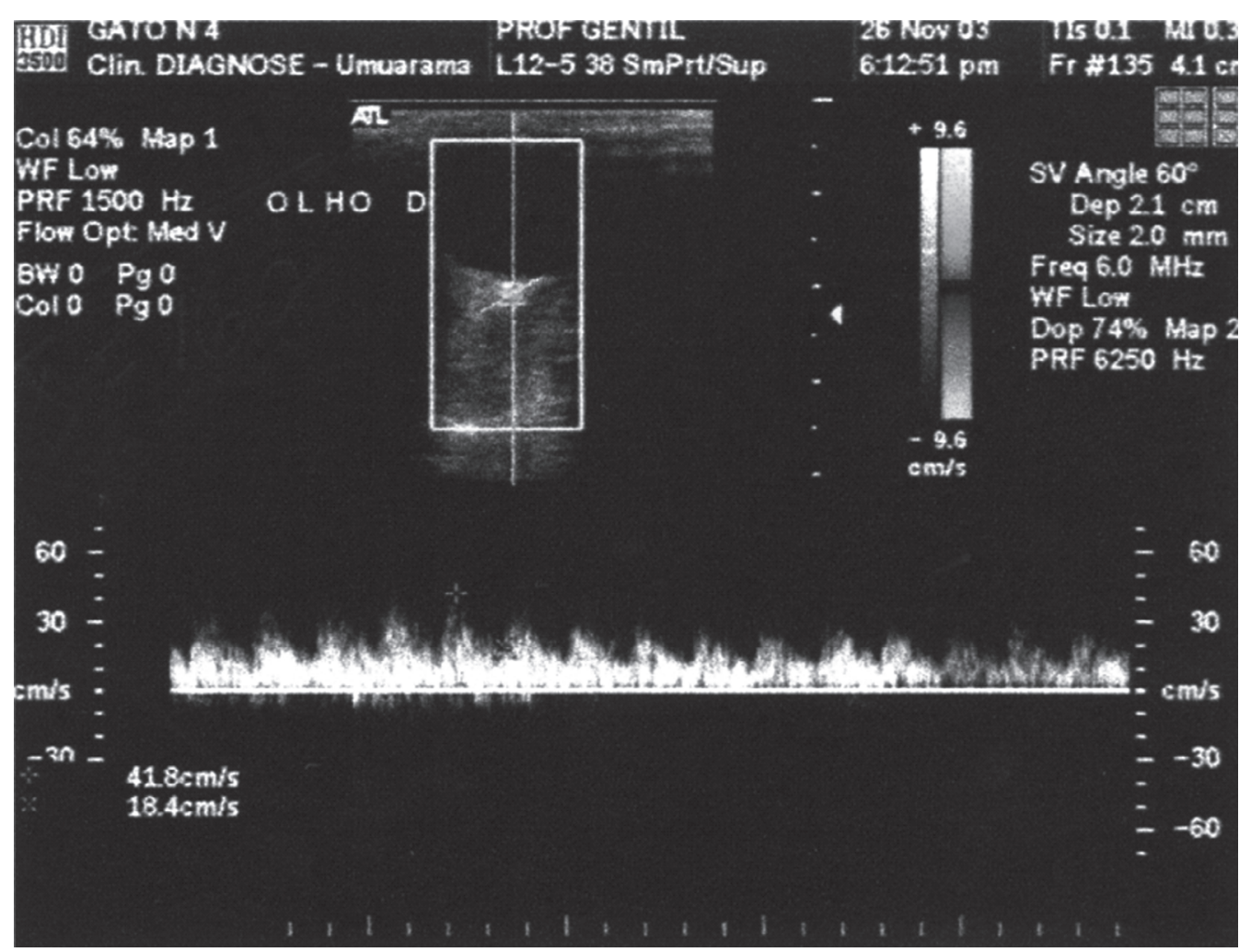

Figura 1 - Imagem ultra-sonográfica do bulbo ocular direito de um gato sem raça definida, obtida com aparelho Toshiba ATL/ HDI 3500, e transdutor setorial eletrônico de 6,0 MHz. Aplicação da função eco-doppler, para determinação do fluxo sangüíneo da artéria oftálmica externa. O cursor se apresenta colocado sobre a artéria com o ângulo de insonação corrigido em $60^{\circ}$. O gráfico na parte inferior da imagem apresenta a oscilação do fluxo no intervalo de tempo determinado, os valores abaixo se referem à média no intervalo de tempo, para sístole e diástole, em centímetros por segundo

estado proporcionou a implantação do cateter na artéria femoral, sem complicações cirúrgicas ou anestésicas em todos os animais deste experimento. Possibilitou ainda o transporte e a realização do exame sonográfico e da avaliação da PAM. Nenhum animal apresentou sinais de dor ou desconforto durante a realização dos procedimentos descritos.

As doses anestésicas de tiletamina que podem produzir hipertensão, relatadas por Cullen e Reynoldson ${ }^{7}$; Lin et al. ${ }^{6}$; Pablo e Bailey ${ }^{8}$ e Tracy, Short e Clark ${ }^{9}$, não foram utilizadas nesse experimento. Dessa forma não se observou aumento significativo da PAM que possa ser atribuído ao procedimento anestésico, o que foi relacionado à dose de fármacos utilizada. A hipotensão observada em gatos anestesiados com tiletamina e zolazepam é referida com o uso de doses altas, o que produz uma diminuição da resistência vascular periférica e um aumento do leito, que mesmo com o aumento do débito cardíaco mantém a pressão abaixo dos valores de referência, de acordo com Cullen e Reynoldson ${ }^{7}$; Lin et al. ${ }^{6}$; Pablo e Bailey ${ }^{8}$ e Tracy, Short e Clark ${ }^{9}$. No presente experimento somente um dos gatos anestesiados e examinados, o G7, apresentou PAM média de $85 \mathrm{mmHg}$, o que se relacionou com aumento na velocidade de fluxo na artéria oftálmica externa, ligeiramente acima dos valores médios dos outros gatos. Este fato pode se explicado pela demora na realização do exame ultrasonográfico, com necessidade de nova administração de fármacos anestésicos, o que levou a uma sobre-dose anestésica que produziu o quadro observado.

Por serem animais "de rua" alojados no SAAU, e apesar do período de adaptação, os gatos se apresentavam agressivos no 
Tabela 2 - Valores médios do fluxo sangüíneo, em centímetros por segundo, na artéria oftálmica externa de gatos sem raça definida, anestesiados com tiletamina e zolazepam, obtidos por fluxometria com Doppler colorido. Onde, OD-S corresponde ao fluxo na artéria do olho direito durante a sístole ventricular; OD-D, na a. no olho direito durante a diástole; OE-S, na a. no olho esquerdo durante a sístole; e OE-D, na a. no olho direito durante a diástole

\begin{tabular}{|c|c|c|c|c|}
\hline Animais & OD-S & OD-D & OE-S & OE-D \\
\hline G1 & 27,83 & 19,15 & 41,70 & 22,05 \\
\hline G2 & 38,87 & 22,83 & 43,47 & 24,77 \\
\hline G3 & 54,20 & 28,97 & 56,25 & 35,65 \\
\hline G4 & 47,63 & 23,93 & 57,15 & 37,85 \\
\hline G5 & 76,20 & 56,15 & 45,73 & 26,43 \\
\hline G6 & 65,90 & 42,90 & 56,07 & 33,80 \\
\hline G7 & 62,73 & 42,73 & 75,37 & 52,73 \\
\hline G8 & 45,37 & 23,63 & 56,83 & 36,20 \\
\hline G9 & 52,73 & 29,70 & 43,83 & 22,27 \\
\hline G10 & 29,53 & 13,93 & 24,20 & 14,20 \\
\hline G11 & 34,90 & 15,00 & 28,40 & 19,50 \\
\hline G12 & 36,90 & 22,45 & 36,90 & 20,40 \\
\hline G13 & 27,40 & 14,70 & 23,10 & 9,70 \\
\hline G14 & 24,90 & 13,75 & 31,75 & 20,45 \\
\hline G15 & 34,30 & 20,97 & 43,17 & 23,53 \\
\hline G16 & 35,17 & 21,40 & 38,10 & 24,75 \\
\hline G17 & 34,55 & 9,85 & 36,80 & 20,40 \\
\hline G18 & 29,45 & 19,55 & 38,45 & 20,05 \\
\hline G19 & 32,30 & 17,80 & 39,00 & 22,80 \\
\hline G20 & 35,10 & 19,50 & 38,80 & 21,40 \\
\hline Média & 41,30 & 23,95 & 42,75 & 25,45 \\
\hline Desvio-padrão & 14,28 & 11,46 & 12,64 & 9,61 \\
\hline
\end{tabular}

momento da contenção para anestesia, o que aumentou os níveis de estresse com provável liberação de catecolaminas. Este fato, associado ao desconforto pela administração intra-muscular dos agentes anestésicos, provavelmente foi parcialmente responsável pela verificação de PAM acima dos valores de referência citados por Detweiler ${ }^{10}$. O desconforto pela aplicação intramuscular de tiletamina associada a zolazepam foi relatado por Lin et al. ${ }^{6}$ e Tracy, Short e Clark ${ }^{9}$.

O método direto utilizado para aferir a PAM se mostrou eficiente, porém a canulação direta da artéria femoral, sem sedação ou anestesia, se mostrou impossível nos animais utilizados, apesar de ser citada por Carr ${ }^{11}$, Grosenbaugh e Muir ${ }^{12}$, Jones ${ }^{13,14}$, Labato e Ross ${ }^{15}$ e Waddell ${ }^{16}$. Tal fato pode ser atribuído à origem dos animais, pois todos eram animais abandonados, com pouco contato com o ser humano, que viviam em gatis coletivos no SAAU. Apesar do período de adaptação em que se procurou manipular os animais para que se tornassem mais dóceis, não foi conseguida a melhoria na relação com os animais, permanecendo os mesmos indóceis e agressivos.

A técnica para aplicação do cateter na artéria femoral se mostrou relativamente fácil com os animais anestesiados, e o treino tornou o procedimento mais rápido e eficiente, corroborando as afirmações de Grosenbaugh e Muir ${ }^{12}$. Por ser considerada a mais precisa e confiável, a técnica de aferição da PAM por método direto foi escolhida entre as demais, apesar dos riscos de complicações relatados por Grosenbaugh e Muir ${ }^{12}$ e observados em alguns animais nesse trabalho. A formação de hematoma observada, não apresentou problemas para os animais nos dias subseqüentes ao exame. A isquemia e a necrose, que levaram a amputação do membro de alguns animais, 
Tabela 3 - Valores médios do índice de resistência da artéria oftálmica externa de gatos sem raça definida, anestesiados com tiletamina e zolazepam. Onde, OD representa o olho direito e OE o olho esquerdo

\begin{tabular}{ccc}
\hline Animais & OD & OE \\
\hline G1 & 0,32 & 0,47 \\
G 2 & 0,40 & 0,44 \\
G & 0,46 & 0,35 \\
G4 & 0,5 & 0,34 \\
G5 & 0,26 & 0,41 \\
G6 & 0,35 & 0,39 \\
G7 & 0,31 & 0,3 \\
G8 & 0,47 & 0,35 \\
G9 & 0,46 & 0,49 \\
G10 & 0,53 & 0,31 \\
G11 & 0,57 & 0,31 \\
G12 & 0,39 & 0,44 \\
G13 & 0,46 & 0,58 \\
G14 & 0,43 & 0,35 \\
G15 & 0,39 & 0,47 \\
G16 & 0,39 & 0,34 \\
G17 & 0,45 & 0,44 \\
G18 & 0,33 & 0,39 \\
G19 & 0,44 & 0,42 \\
G20 & 0,44 & 0,44 \\
\hline Média & 0,4175 & 0,4015 \\
\hline Desvio padrão & 0,0774 & 0,0719 \\
\hline Teste t de student pareado: $\mathrm{t}=0,6257$ e p $=0,5390$, interpretação: não existe diferença significativa entre o:
\end{tabular}

olhos para o indice de resistência da artéria oftálmica extema.

foi a alteração mais significativa, o que torna o procedimento de alto risco para gatos.

Devido à variação entre os estudos para determinar os valores limites para a pressão arterial em gatos, o animal é considerado hipertenso quando os valores superam 190/140 mmHg, de acordo com Labato e Ross ${ }^{15}$. A PAS em gatos com doença retiniana hipertensiva tipicamente é maior que $200 \mathrm{mmHg}$. Outra anormalidade consistente inclue azotemia. ${ }^{4,17,18,19,20}$ Nenhum dos animais examinados apresentava qualquer indício de hipertensão sistêmica ou retinopatia hipertensiva, nem qualquer outra afecção que pudesse comprometer os resultados obtidos. A PAM obtida apresentou valores médios acima dos considerados normais por Detweiler ${ }^{10}$. Os valores considerados normais, na realidade, são aqueles observados em uma curva de distribuição de Gauss da variação populacional para a espécie. Trata-se de um critério de normalidade que surge da avaliação da morbidade em relação a um fenômeno, a PA, de distribuição estatística contínua na população, segundo Riva ${ }^{21}$.
Nesse trabalho a diferença existente entre os valores considerados normais e aqueles obtidos, pode ser em parte atribuída ao procedimento anestésico utilizado e a liberação de catecolaminas pelo estresse sofrido pelo animal durante a contenção física. A afirmação de Riva ${ }^{21}$, entretanto, faz com que os valores obtidos possam ser considerados dentro da normalidade, pois os animais se apresentavam hígidos antes do procedimento.

O fluxo sangüíneo na artéria oftálmica externa em gatos se manteve dentro de limites estreitos entre os animais, não apresentando diferenças significativas entre os olhos, a principal diferença encontrada foi de acordo com o momento da revolução cardíaca. Isso denota a influência da póscarga no volume sangüíneo circulante, e conseqüentemente no fluxo sangüíneo dessa artéria. Porém esta não é a única influência sofrida pelo fluxo durante a passagem do sangue pelo interior da artéria. De acordo com Cingolani ${ }^{1}$, Grosenbaugh e Muir ${ }^{12}$, Silverthorn ${ }^{22}$ e Singii ${ }^{23}$, além do volume sangüíneo ejetado, também a resistência e a 
elasticidade da parede do vaso sangüíneo ditariam a velocidade de fluxo no interior do vaso, fato que também contribui para a formação e determinação de pressão arterial sistêmica. Assim espera-se que a velocidade de fluxo sangüíneo no interior da artéria oftálmica seja maior durante a sístole e menor na diástole em qualquer artéria em condições normais.

Os efeitos das variações na pressão arterial sistêmica no exame eletrorretinográfico de gatos, demonstraram evidências da existência de um sistema de autoregulação retiniano, nos estudos de Demant, Nagahara, Niemeyer ${ }^{24}$. Neste estudo, examinaram gatos anestesiados e submetidos a fármacos que aumentaram e diminuíram a pressão a valores extremos. Através das evidencias eletrofisiológicas observadas, puderam afirmar que a estabilidade da onda $b$ durante as oscilações de PAM, entre 55 e $225 \mathrm{mmHg}$, denotou a evidência de um mecanismo de auto-regulação que estabiliza a circulação retiniana. Tal mecanismo pode elucidar o fato observado no animal G7 no presente trabalho, que teve sua PAM reduzida a valores abaixo da média, enquanto sua velocidade de fluxo na artéria oftálmica externa aferida, foi acima dos valores médios dos outros animais examinados. A velocidade do fluxo sangüíneo no interior de artérias pode ser ditada por fatores locais que controlem o diâmetro e a resistência da parede do vaso em questão. Existem mecanismos de controle local da pressão arterial, de acordo com o tipo de tecido e suas necessidades de fluxo e de trocas gasosas. Este fato se dá por alguns mecanismos de regulação do tônus da musculatura lisa da parede arterial. Tais mecanismos são independentes dos fatores humorais sistêmicos e do sistema nervoso central. O músculo liso vascular contrai-se em resposta ao estiramento e relaxa quando diminui a tensão a que está submetido. Uma vez que o estiramento da fibra muscular eleva a concentração de intracelular cálcio, supõe-se que a manobra ative os canais de membrana para cátion e/ou a liberação de cálcio pelo retículo sarcoplasmático, n o chamado mecanismo miogênico. A auto-regulação metabólica encontra-se vinculada, de modo particular, à relação oferta/demanda tecidual de oxigênio. Se a oferta é insuficiente, substâncias vasodilatadoras são produzidas localmente, entre elas podese identificar gás carbônico, ácido láctico e concentração de íons hidrogênio, inclusive nos radicais livres. Algumas substâncias sintetizadas na parede vascular são vasoativas, atuando nos mecanismos regionais de regulação de pressão arterial local. Entre estas substâncias pode-se citar o óxido nítrico, o fator hiperpolarizante derivado do endotélio, as endotelinas, prostaglandinas, leucotrienos e apoxiácidos, e ainda os eucosanóides, de acordo com Riva ${ }^{21}$ e Silverthorn ${ }^{22}$.

As observações de Okubo, Gherezghiher e Koss ${ }^{25}$, acerca da fluxometria com laser Doppler aplicada diretamente sobre a artéria ciliar longa posterior de coelhos, verificando as oscilações do fluxo frente às oscilações de pressão arterial, corroboram os achados no gato G7 neste trabalho, uma vez que no final o fluxo sangüíneo se comportou exatamente de forma contrária à pressão arterial, ou seja, quando a pressão diminuiu em relação a média, houve uma tendência em aumentar o fluxo, em relação a média dos outros animais. Tal fato também foi observado por Roth e Pietrzyk ${ }^{26}$, após produzirem isquemia retiniana em gatos.

A ausência de correlação entre a PAM e o fluxo sangüíneo da artéria oftálmica externa em gatos sem raça definida, observada nesse trabalho pode ser explicada pelos achados de Attariwala, Giebs e Glucksberg ${ }^{27}$ em gatos, que verificaram que a resposta arterial ao aumento de pressão não é linear, pois esse sistema não é passivo, confirmando os mecanismos de auto-regulação dos vasos retinianos. Os achados de Okubo, Gherezghiher e Koss ${ }^{25}$ inter-relacionam a 
pressão o fluxo nas artérias oculares, porém verificam a sua tendência inversa, em um mecanismo de compensação. $O$ que se pode suspeitar é que, com o advento da hipertensão, a oscilação da PAM se mantém de forma crônica, e consegue romper os limites do controle local de fluxo das artérias oculares, produzindo alterações retinianas graves.

\section{Conclusão}

Não existe correlação estatística entre o fluxo sangüíneo na artéria oftálmica externa e a PAM nos animais avaliados, sendo a PAM aferida de $144,9 \pm 26,68 \mathrm{mmHg}$ e o fluxo médio de $42 \pm 12 \mathrm{~cm} / \mathrm{s}$ em sístole e 24,5 \pm $10 \mathrm{~cm} / \mathrm{s}$ em diástole, e o índice de resistência médio $0,40 \pm 0,07$.

\section{Correlation between arterial pressure and blood flow in the external ophthalmic artery in cats (felis catus linnaeus, 1758)}

\section{Abstract}

There were used 20 mixed breed cats, both male and female, with body mass between 2 and 4 kilograms, that received anesthesia with tiletamine and zolazepam $(6,0 \mathrm{mg} / \mathrm{kg})$. The femoral artery was assepticale cannulated and a manometer connected to an air column was connected to the catheter. The MAP was surveyed before and every 15 minutes until the end of the ultrasound examination. The flow of the external ophthalmic artery was measured through the ultrasond equipment, with an echo-doppler and a sectorial transducer of $6.0 \mathrm{MHz}$, directly applied to the cornea. Each eye had the artery flow surveyed by the equipment's own device, 3 samples being taken. The vascular resistance index was calculated based on the mean values of systolic and diastolic flow of each vasses. An average value for the MAP of $144.9 \pm 26.68 \mathrm{mmHg}$ and a flow of $14.28 \pm 41.3 \mathrm{~cm} / \mathrm{sec}$ for the external ophthalmic artery in the right eye in systole, $23.95 \pm 11.46$ $\mathrm{cm} / \mathrm{sec}$ in diastole and $42.75 \pm 12.64 \mathrm{~cm} / \mathrm{sec}$ in the left eye in systole, $25.45 \pm 9.61 \mathrm{~cm} / \mathrm{sec}$ in diastole, were verified, there being no significant difference between the eyes. The calculated index of vascular resistance was of $0.4175 \pm 0.0774$ for the external ophthalmic artery in the right eye and $0,4015 \pm 0.0719$ for the left eye, without any significant difference between the eyes. The results point to an intrinsic mechanism of flow control, controlled by local factors in the external ophthalmic artery. The values of the resistance index denote a low flow artery. Concluding, this study revealed the reference values, above cited, for the MAP and the blood flow in the external ophthalmic artery in mixed breed cats, anesthetized with tiletamine and zolazepam, and the information that there is no correlation between these values.
Key words:

Cats.

Ophthalmology. Blood pressure. Rheology. Ophthalmic artery.

\section{Referências}

1 CINGOLANI, H. E. Hemodinâmica: pressão arterial e débito cardíaco. In: CINGOLANI, H. E.; HOUSSAY, A. B. Fisiologia humana de Houssay. 7. ed. Porto Alegre: Artmed, 2004. cap.25, p. 307-316.

2 DINIZ, A. L. D. et al. Dopplervelocimetria colorida dos vasos orbitais: técnica de exame e anatomia vascular. Radiol Bras., São Paulo, v. 37, n. 4, p. 287-290, 2004.
3 MORGAN, R. V. Sistemic hypertension in four cats: ocular and medical findings. JAAHA, Denver, v. 22, n. 615, p. 11-16, 1986.

4 NASISSE, M. P. Feline ophthalmology. In: GELATT, K. N. Vet ophthalmol. $2^{\text {nd }}$ ed. Philadelphia: Lea e Febinger, 1991. cap.14, Seção 3, p. 562.

5 ELLIOTT, J. et al. Feline hypertension: clinical findings and response to antihypertensive treatment in 30 cases. J Small Anim Pract., v. 42, n. 3, p. 122-129, 2001. 
$6 \mathrm{LIN}, \mathrm{H}$. C. et al. Telazol - A review of its pharmacology and use in veterinary medicine. J Vet Pharmacol Therap., v. 16, p. 383-418, 1992.

7 CULLEN, L. K.; REYNOLDSON, J. A. Effects of tiletamine/zolazepam premedication on propofol anaesthesia in dogs. The Vet Rec., v. 140, n. 5, p. 1363 1366, 1997.

8 PABLO, L. S.; BAILEY, J. E. Etomidate and telazol. Vet Clin North Am Small Anim Pract, v. 29, n. 3, p. 779 792, 1999.

9 TRACY, C. H.; SHORT, C. E.; CLARK, B. C. Comparing the effects of intravenous and intramuscular administration of telazol. Vet Med, v. 83, n. 1, p. 104108, 1988.

10 DETWEILER, D. K. Mecanismos de controle do sistema circulatório. In: SWENSON, M. J.; REECE, W. O. Dukes: fisiologia dos animais domésticos. 11. ed. Rio de Janeiro: Guanabara Koogan. 1996. cap. 10, p. 170-208.

11 CARR, A. P. Blood pressure: Advancing clinical undertanding. Adv in Small Anim Med and Surg., v. 14, n. 2, p. 636-637, 2001.

12 GROSENBAUGGH, D. A.; MUIR, W. W. Blood pressure monitoring. Vet Med., v. 93, n. 1, p. 48-59, 1998.

13 JONES, J. L. Noninvasive monitoring techniques in anesthetized animals. Vet Med., v. 91, n. 4, p. 326336, 1996.

14 JONES, J. L. Invasive monitoring techniques in anesthetized animals. Vet Med., v. 91, n. 4, p. 337 339, 1996.

15 LABATO, M. A.; ROSS, L. A. Diagnóstico y tratamiento de la hipertension. In: AUGUST, J. R. Consultas em medicina interna felina. Buenos Aires: Inter-médica, 1993. cap.37, Seção V, p. 323-332.

16 WADDELL, L. S. Direct blood pressure monitoring. Clinic Tech in Small Animal Pract. v. 15, n. 3, p. 111 118, 2000.

17 BARTGES, J. W.; WILLIS, A. M.; POLZIN, D. J. Hypertension and renal disease. Vet Clin North Am Small Anim Pract., v. 26, n. 6, p. 1331-1345, 1996.

18 HENIK, R. A. Systemic hypertension and its management. Vet Clin North Am Small Anim Pract., v. 27, n. 6, p. 1355-1372, 1997.

19 SANSOM, J.; BODEY, A. Ocular signs in four dogs with hipertension. The Vet Rec, v. 140, n. 3, p. 593598, 1997.

20 BODEY, A. R.; SANSOM, J. Epidemiological study of blood pressure in domestic cats. J Small Anim Pract., v. 39, n. 12 , p. 567-573, 1998.

21 RIVA, I. Controle da pressão arterial. In. CINGOLANI, H. E.; HOUSSAY, A. B. Fisiologia humana de Houssay. 7. ed. Porto Alegre: Artmed, 2004. cap. 28, p. 345-363.

22 SILVERTHORN, D. E. Fluxo sangüíneo e controle da pressão arterial. In: SILVERTHORN, D. E.; OBER, W. C.; GARRISON, C. W.; SILVERTHORN, A. C. Fisiologia humana: uma abordagem integrada. 2 ed. São Paulo: Manole. 2003. cap 15, p. 443-473.

23 SINGI, G. Pressão arterial. In: SINGI, G. Fisiologia dinâmica: texto básico para os cursos de Ciências Biológicas. São Paulo: Atheneu, 2001. cap. 11, p. 131138.

24 DEMANT, E.; NAGAHARA, K.; NIEMEYER, G. Effects of changes in systemic blood pressure on the eletroretinogram of the cat: evidence for retinal autoregulation. Invest Ophthalmol \& Vis Sci., v. 23, n. 5, p. 683-687, 1982.

25 OKUBO, H.; GHEREZGHIHER, T.; KOSS, M. C. Long posterior ciliary arterial blood flow and systemic blood pressure. Invest Ophthalmol \& Vis Sci, v. 31, n. 5, p. 819-826, 1990.

26 ROTH, S.; PIETRZYK, Z. Blood flow after retinal ischemia in cats. Invest Ophthalmol \& Vis Sci, v. 35, n. 8, p. 3209-3217, 1994.

27 ATTARIWALA, R.; GIEBS, C. P.; GLUCKSBERG, $M$. R. The influence of elevated intraocular pressure on vascular pressures in the cat retina. Invest Ophthalmol \& Vis Sci., v. 35, n. 3. p. 1019-1025, 1994.

28 BROWN, S. A.; HENIK, R. A. Diagnosis and treatment of systemic hypertension. Vet Clin North Am Small Anim Pract., v. 28, n. 6, p. 1481-1494, 1998.

29 MORGAN, R. V. Ultrasonography of retrobulbar diseases of the dog and cat. JAAHA, Denver, v. 25, n. 4 p.393-399, 1989. 